\title{
Mixed Conductors under Light: On the Way to Solid Oxide Photo-Electrochemical Cells
}

\author{
J. Fleig ${ }^{\mathrm{a}}$, G. Walch ${ }^{\mathrm{a}}$, G. C. Brunauer ${ }^{\mathrm{b}}$, B. Rotter ${ }^{\mathrm{b}}$, E. Esmaeli $^{\mathrm{b}}$, J. Summhammer ${ }^{\mathrm{c}}$, \\ A. K. Opitz ${ }^{\text {, }}$, and K. Ponweiser ${ }^{b}$ \\ a Institute of Chemical Technologies and Analytics, Technische Universität Wien, Vienna, \\ Austria \\ ${ }^{\mathrm{b}}$ Institute of Energy Systems and Thermodynamics, Technische Universität Wien, \\ Vienna, Austria \\ ${ }^{c}$ Institute of Atomic and Subatomic Physics, Technische Universität Wien, Vienna, \\ Austria
}

\begin{abstract}
Photo-electrochemical cells based on aqueous electrolytes have been heavily investigated for their potential to convert light into chemical energy. In contrast, very little is known on the possibility of transferring photon energy into chemical energy in high temperature solid state electrochemical cells. This is true despite the fact that solid electrolyte based systems can be operated very successfully as fuel and electrolysis cells (SOFCs/SOECs). Here, we report results on the interaction of mixed conducting oxides with light in cells using oxide ion conductors and operating at 350$500^{\circ} \mathrm{C}$. One type of system contains a high temperature solar cell based on $\mathrm{SrTiO}_{3}$ and $\mathrm{LaCrO}_{3}$. It allows oxygen pumping and thus chemical energy storage under UV light. In another type of system UV light produces a time dependent voltage that includes two processes potentially also enabling energy storage: First, again a photovoltaic effect is present; second, the illuminated mixed conducting oxide changes its stoichiometry and thus leads to a battery type (Nernstian) voltage.
\end{abstract}

\section{Introduction}

Photon driven electrochemical reactions may contribute to future sustainable energy supply. Many different oxides (e.g. $\mathrm{TiO}_{2}$ or $\mathrm{Fe}_{2} \mathrm{O}_{3}$ ) have been tested so far to run the most prominent photon driven reaction, namely photo-(electro-)chemical water splitting. However, despite strong efforts efficiency and/or materials stability are still not sufficient for widespread application (1-7). In the vast majority of those studies the photoelectrochemical reaction takes place in aqueous solution close to room temperature. $\mathrm{ON}$ the other hand, photo-electrochemistry based on solid oxide electrolytes is an almost unexplored field. In such cells, operation temperatures of several hundred ${ }^{\circ} \mathrm{C}$ are required to enable sufficient oxide ion conduction. Very little knowledge is available on the experimental realization of such cells and on their problems. UV light was shown to accelerate oxygen incorporation into $\mathrm{SrTiO}_{3}(8)$ and $\mathrm{TiO}_{2}(9)$ and a theoretical model of a solid state photo-electrochemical cell including a mixed conducting electrode was described in Ref. (10). 
In this contribution, two different approaches are employed to investigate the possibilities of energy conversion from photon energy to chemical energy using solid oxide ion conductors. The first approach is based on combining photovoltaics (PV) and voltage driven electrochemical (EC) cells (e.g. electrolysis cells). Already now powerful photovoltaic systems can be coupled to any kind of independently operating electrolysis cell. However, instead of relying on independent PV and EC systems, the goal of our first approach was to fabricate a single solid oxide photo-electrochemical cell (SOPEC) that directly uses the electrical energy in its electrochemical cell (EC) part. The corresponding Cell Type I is sketched in Fig. 1: The bottom electrode of the photovoltaic (PV) cell part is a shared electrode and also acts as top electrode of the electrochemical cell. Since solid state electrochemical cells require high temperatures for operation, the PV cell part has to be exposed to high temperature as well and thus a novel type of solar cell operating at temperatures up to $500^{\circ} \mathrm{C}$ had to be developed.

The second approach does not combine two complete cells (i.e. a PV and an EC cell). Rather, a (UV-)light absorbing mixed ionic and electronic conductor (MIEC) is in direct contact with a solid electrolyte (Y-doped $\mathrm{ZrO}_{2}$ ) and metallic electrodes or current collectors are used on both sides. This is also illustrated in Fig. 1 (Cell Type II). As MIECs either $\mathrm{TiO}_{2}$ thin films or $\mathrm{SrTiO}_{3}$ single crystals were employed (Cell Type IIa and IIb). The main features occurring during illumination are discussed for both cell types. For the first cell emphasis is put on the resulting current of the operating cell which enables electrochemical pumping of oxygen. For the second type, voltage effects under illumination are presented and interpreted.
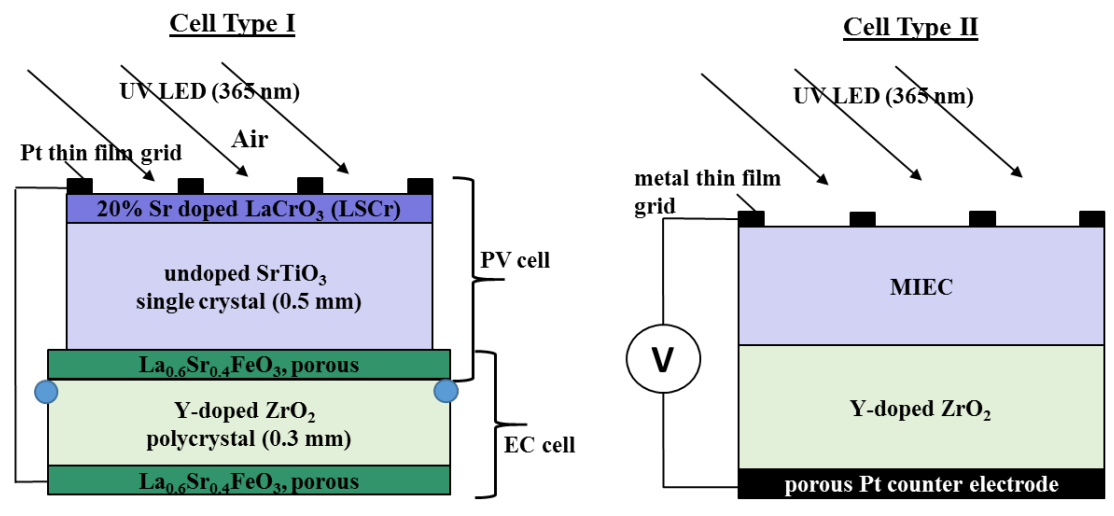

low $\mathbf{p}\left(\mathrm{O}_{2}\right)$
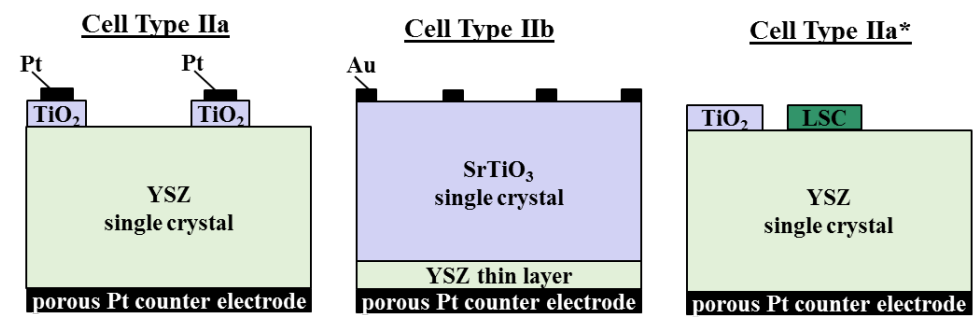

Figure 1. Sketches of the two cell types used in this study. Cell Type I includes a photovoltaic (PV) and an electrochemical (EC) part and the entire SOPEC is then operated under short circuit condition. Cell Type II is realized in two different manners, once with a thin $\mathrm{TiO}_{2}$ layer on a thick electrolyte (IIa) and once with thick $\mathrm{SrTiO}_{3}$ and a thin electrolyte layer (IIb). A modified version of IIa (IIa*) has additional $\mathrm{La}_{0.6} \mathrm{Sr}_{0.4} \mathrm{CoO}_{3}$ $\delta$ (LSC) thin film stripes on top of the electrolyte. 


\section{Experimental}

Cell Type I: A combined PV and EC cell with shared electrode

A ca. $500 \mathrm{~nm}$ thin layer of $\mathrm{La}_{0.8} \mathrm{Sr}_{0.2} \mathrm{CrO}_{3}$ ( $\mathrm{LSCr}$ ) was deposited on a nominally undoped $\mathrm{SrTiO}_{3}$ (100) single crystal (Crystec $\mathrm{GmbH}$, Germany, $0.5 \mathrm{~mm}$ thickness, 10 $\mathrm{mm} \times 10 \mathrm{~mm}$ ) by pulsed laser deposition (PLD). A Pt current collector grid was deposited on top of the LSCr layer with stripe width and distance of $10 \mu \mathrm{m}$ and $40 \mu \mathrm{m}$, respectively (sputter deposition and photolithographic process). On a circular tetragonal zirconia polycrystal substrate (Kerafol, $3 \mathrm{~mol} \% \mathrm{Y}_{2} \mathrm{O}_{3}, 300 \mu \mathrm{m}$ thickness, $2 \mathrm{~cm}$ in diameter) two porous mixed conducting $\mathrm{La}_{0.6} \mathrm{Sr}_{0.4} \mathrm{FeO}_{3-\delta}$ (LSF) electrodes were deposited from a paste. The $\mathrm{SrTiO}_{3}$ single crystal with $\mathrm{LSCr}$ top layer was placed on this electrochemical cell and the entire oxide sequence was heated to $850^{\circ} \mathrm{C}$ for $5 \mathrm{~h}$ in ambient air to mechanically link the two sub-systems to form a solid oxide photoelectrochemical cell (SOPEC).

The resulting solid oxide cell was mounted in a tube furnace such that two different gas compartments resulted. The PV cell and the top LSF electrode of the EC cell were held in ambient air, while the bottom part of the EC cell could be exposed to low $\mathrm{p}\left(\mathrm{O}_{2}\right)$, in our case a gas flow of nitrogen with ca. $640 \mathrm{ppm}$ remaining oxygen due to non-ideal gas tightness (measured by an oxygen gas sensor).

At temperatures between 400 and $500^{\circ} \mathrm{C}$ the SOPEC was illuminated by UV light using a $10 \mathrm{~W}$ LED (LED ENGIN, San Jose USA) with $365 \mathrm{~nm}$ and a light intensity at the sample surface of ca. $300 \mathrm{~mW} / \mathrm{cm}^{2}$. In a first step the PV cell itself was characterized (current voltage curve). Then, the top and bottom electrodes were short circuited (SC), see Fig. 1, and the entire driving force of the photovoltaic cell was used to drive a current. This requires an ionic current in the electrolyte and thus oxygen pumping from the low to the high pressure side. More details on these measurements can be found in Ref. (11).

\section{Cell Type II: A single cell approach}

In the second approach a UV-light-absorbing mixed ionic and electronic conductor (MIEC) was directly combined with a zirconia based solid electrolyte. Two different MIECs with very different thicknesses were employed: Cell Type IIa was prepared by sputter depositing $\mathrm{TiO}_{2}$ thin films (thickness in the $100 \mathrm{~nm}$ range) on a $9.5 \mathrm{~mol} \%$ yttria stabilized $\mathrm{ZrO}_{2}$ (YSZ) single crystals (Crystec, Germany, $0.5 \mathrm{~mm}$ thickness). The resulting $\mathrm{TiO}_{2}$ was largely in the anatase phase (measured by X-ray diffraction). On top of this titania layer, a Pt layer (ca. $100 \mathrm{~nm}$ ) was sputter deposited and different microstructures of this layer sequence were finally realized by photolithography and ion beam etching. One type of microelectrode prepared in this way is sketched in Fig. 1: A $\mathrm{TiO}_{2}$ circle with a diameter of $300 \mu \mathrm{m}$ covered by a $200 \mu \mathrm{m}$ Pt circle. In other cases a Pt grid or even a dense Pt layer was used on the titania microelectrodes. Systematic variations of light effects caused by the Pt coverage were not observed. It can thus be assumed that also the titania part covered by Pt is illuminated by UV light reflected at the porous Pt paste counter electrode. The voltage between Pt top electrode and Pt counter electrode was measured in air or Ar gas before, during and after UV light illumination (10 W LED (LED ENGIN, San Jose USA), $365 \mathrm{~nm}$ ). Set temperatures of the heating table used to heat the samples were $400-500^{\circ} \mathrm{C}$; true sample temperatures are slightly lower (by typically $30-40^{\circ} \mathrm{C}$ ) due to asymmetric heating (12). 
The results shown here for $\mathrm{TiO}_{2}$ cells (IIa) are based on experiments with many samples of different $\mathrm{TiO}_{2} / \mathrm{Pt}$ geometry and are considered as representative for the main features found in these extensive studies. Additionally, one experimental result is shown for a further cell geometry with alternating $\mathrm{La}_{0.6} \mathrm{Sr}_{0.4} \mathrm{CoO}_{3-\delta}$ (LSC) and $\mathrm{TiO}_{2}$ thin film stripes. The stripes were approximately $45 \mu \mathrm{m}$ wide with a distance of ca. $10 \mu \mathrm{m}$ (Cell Type IIa*). The LSC layer was deposited by PLD and both layers were micro-structured by photolithography and ion beam etching or lift-off.

In a second measurement series, cells were investigated with undoped $\mathrm{SrTiO}_{3}$ single crystals as MIEC (Cell Type IIb). In this case, an yttria stabilized zirconia layer (ca. 900 nm thickness) was deposited on the bottom side of the $\mathrm{SrTiO}_{3}$ single crystal by pulsed laser deposition from a polycrystalline target ( $8 \mathrm{~mol} \%$ yttria, Tosoh powder). On top of the cell a $\mathrm{Au}$ grid electrode was prepared by sputter deposition and micro-structuring (stripe width $15 \mu \mathrm{m}$, stripe distance $35 \mu \mathrm{m}$ ). As bottom electrode again a porous Pt paste electrode was used. Measurements under illumination were performed in the same manner as for Cell Type IIa.

\section{Results and Discussion}

\section{Cell Type I: A combined PV and EC cell with shared electrode}

Fig. 2a displays the open circuit voltages and the short circuit currents found when illuminating the oxide based PV cell sketched in Fig. 1. Remarkably high voltages of $>900 \mathrm{mV}$ at $400^{\circ} \mathrm{C}$ and $>600 \mathrm{mV}$ at $500^{\circ} \mathrm{C}$ were found. Additional impedance measurements showed that in dark the $\mathrm{LSCr} / \mathrm{SrTiO}_{3}$ interface exhibits a very pronounced resistance which can be attributed to a space charge at the oxide hetero-interface (11). Under UV light this space charge is able to separate electronic charge carriers and thus to create a large voltage even at high temperatures. When short-circuiting the PV cell, currents up to more than $2 \mathrm{~mA}\left(>1 \mathrm{~mA} / \mathrm{cm}^{2}\right)$ are found.
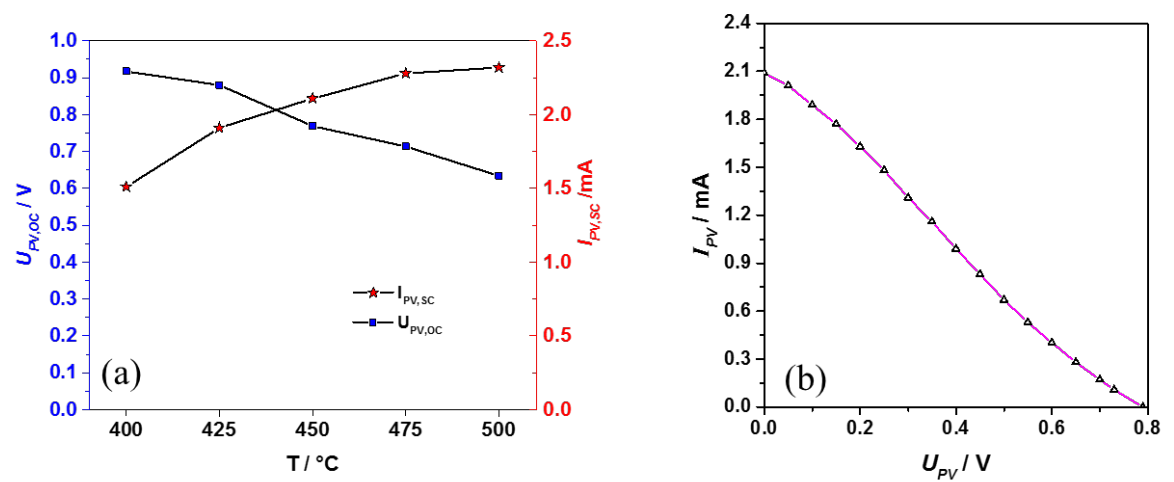

Figure 2. (a) Open circuit voltage (UPV,OC) and short circuit current (IPV,SC) of the illuminated photovoltaic part of the entire SOPEC (Type I) in air, measured at different temperatures. (b) Current voltage curve of the illuminated $\mathrm{PV}$ cell at $450^{\circ} \mathrm{C}$.

A complete current voltage curve is shown in Fig. $2 \mathrm{~b}$ for $450^{\circ} \mathrm{C}$. Additional details on these experiments are given in Ref. (11), including further information on the resistive contributions of $\mathrm{SrTiO}_{3}$ bulk and space charges. These measurement show that even at temperatures being sufficiently high to operate solid state electrochemical cells 
substantial photovoltages can be induced by UV light and those might act as the driving force for subsequent electrochemical energy storage.

Such an energy storage process was realized by short circuiting the entire SOPEC (see Fig. 1) and thus internally consuming the entire driving force due to illumination of the PV cell part to obtain maximal current flow also in the EC cell part. In this case, different gases (air and nitrogen with some remaining $\mathrm{O}_{2}$, respectively) were used at the two sides of the SOPEC. Fig. 3a shows the voltage measured at the EC cell part at $450^{\circ} \mathrm{C}$ and Fig. $3 \mathrm{~b}$ reveals short circuit currents in the $0.8 \mathrm{~mA}$ range. Since only ionic current is possible in the zirconia electrolyte, electrochemical reactions have to be involved: Oxygen is reduced on the low $\mathrm{p}\left(\mathrm{O}_{2}\right)$ bottom side and pumped to the air side, where oxygen is again released from the electrolyte via an oxidation reaction. This type of reaction is confirmed by the oxygen partial pressure change found in the lower compartment of the cell during illumination. Fig. 3c indicates a change from ca. $640 \mu \mathrm{bar}$ to $400 \mu \mathrm{bar}$. Accordingly, chemical energy is stored since oxygen is pumped against its chemical potential gradient.
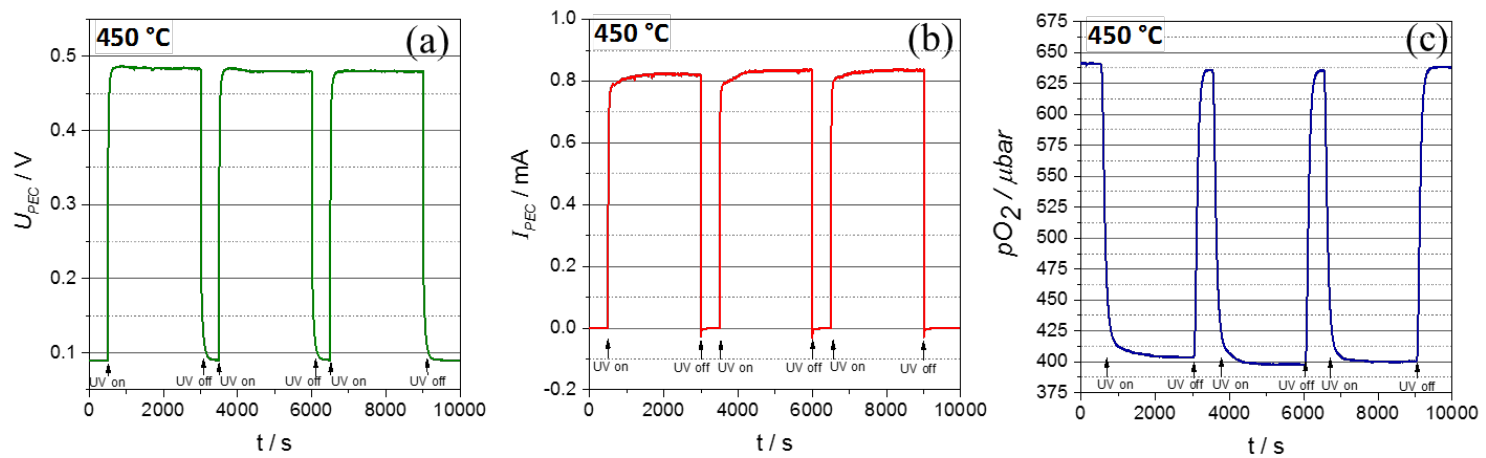

Figure 3. (a) Voltage (UPEC) at the electrochemical part of the short-circuited SOPEC (Type I) at $450^{\circ} \mathrm{C}$ with and without illumination. The top part of the cell was in ambient air, the bottom part in a flow of nitrogen with a remaining oxygen partial pressure of ca. $640 \mu$ bar. (b) Current in the same cell. (c) Oxygen partial pressure variation in the bottom compartment of the SOPEC, indicating oxygen pumping from low to high pressures under illumination.

The voltage measured at the EC cell during illumination and short-circuiting of the entire SOPEC (ca. $480 \mathrm{mV}$ ) includes a Nernstian contribution of almost $100 \mathrm{mV}$ due to the oxygen partial pressure difference as well as the sum of all overpotentials in the operating electrochemical cell part (electrodes and electrolyte). All together, the light induced open circuit voltage of the PV cell is thus consumed by significant internal resistances of both PV and EC cell parts and by the Nernst voltage. More details on such measurements with a detailed interpretation of the voltage losses in the entire SOPEC and on the balance of current and oxygen pumping are given in Ref. (11).

\section{Cell Type II: A single cell approach}

Fig. 4 displays three typical voltage responses of Type Ila samples with $\mathrm{TiO}_{2} / \mathrm{Pt}$ on YSZ single crystals exposed to UV. A certain offset voltage was always found before illumination, with (negative) values up to a few $10 \mathrm{mV}$. The detailed mechanism causing this offset is not known yet and its discussion is beyond the scope of this paper; only UV 
induced deviations from this offset are considered. A rapid jump to negative voltages at the $\mathrm{TiO}_{2} / \mathrm{Pt}$ side is found after switching on UV light (ca. $100-200 \mathrm{mV}$ at $400^{\circ} \mathrm{C}$ set temperature). This jump is followed by a slower change towards less negative voltages. The change often levels off after some time with several ten to more than hundred $\mathrm{mV}$ still remaining between $\mathrm{TiO}_{2} / \mathrm{Pt}$ and counter electrode. After switching off UV light, the voltage does not immediately drop back to its starting value, but overshoots the original offset voltage to positive values of several $10 \mathrm{mV}$. Only on a longer time scale the starting value is again reached. Tests with red light of the same intensity showed that all these effects are not thermal, indicating that indeed electron-hole excitation in the semiconducting titania is involved.

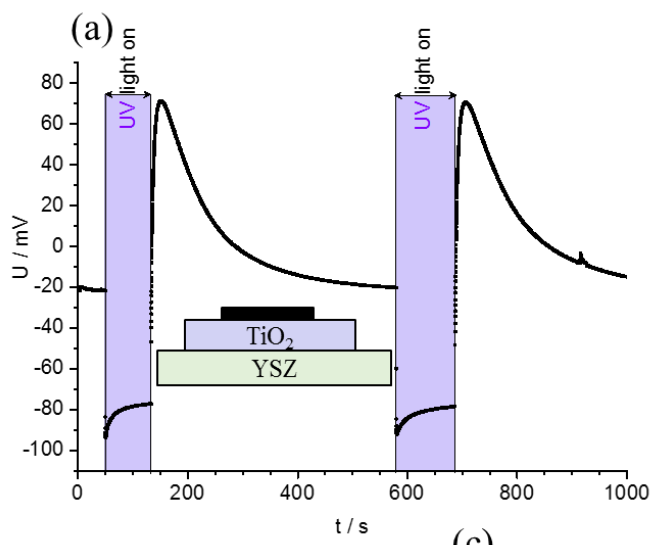

(b)
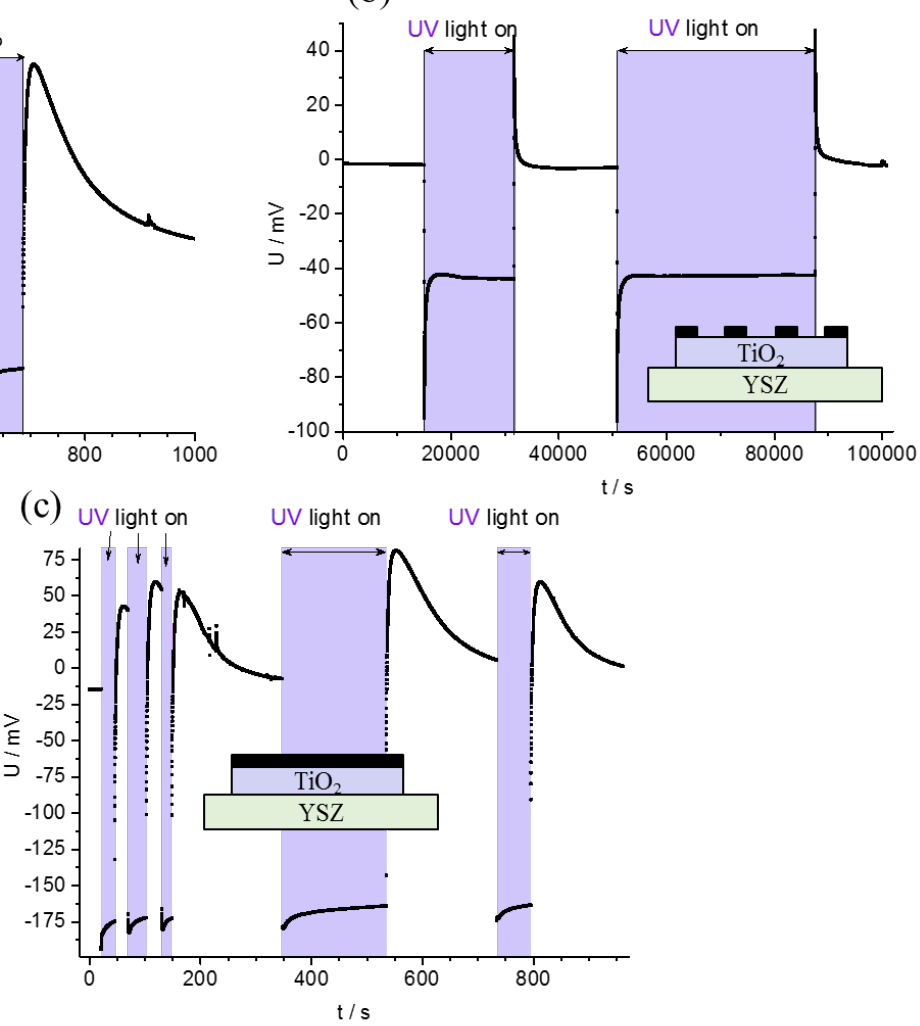

Figure 4. Open circuit voltage of Cell Type IIa with $\mathrm{TiO}_{2}$ microelectrodes on $\mathrm{YSZ}$ with and without illumination for three different $\mathrm{Pt}$ current collector geometries. (a) Smaller Pt circle on $\mathrm{TiO}_{2}$ in air at $400^{\circ} \mathrm{C}$ set temperature, (b) $\mathrm{Pt}$ grid on $\mathrm{TiO}_{2}$ in argon at $500^{\circ} \mathrm{C}$ set temperature, (c) Pt full coverage of $\mathrm{TiO}_{2}$ in air at $400^{\circ} \mathrm{C}$ set temperature.

A very similar type of voltage response to UV light is found for Cell Type IIb with an illuminated $\mathrm{SrTiO}_{3}$ single crystal and YSZ layer beneath. Here, the offset voltage in dark is rather large and may even exceed $-100 \mathrm{mV}$. In Fig. 5 it is shown that again a negative voltage develops very quickly under UV illumination, with values of several hundred $\mathrm{mV}$ between $\mathrm{Au}$ current collector and counter electrode. On a longer time scale this voltage relaxes to much less negative values and then remains almost constant. After switchingoff the UV light the voltage quickly jumps to positive values and very slowly relaxes towards the original offset value, partly with complex time dependencies. The voltage changes during relaxation without light may exceed $200 \mathrm{mV}$. 


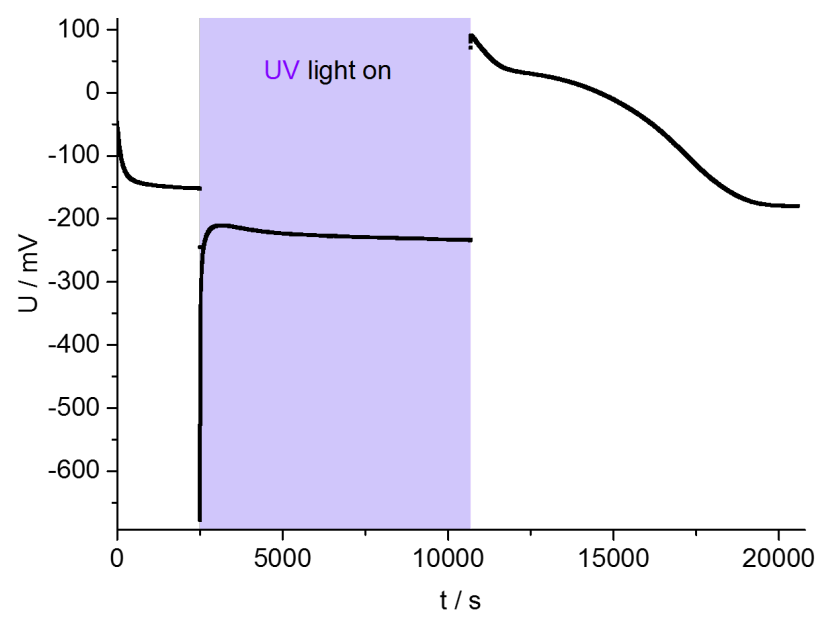

Figure 5. Open circuit voltage of Cell Type IIb with Au current collector grid on a $\mathrm{SrTiO}_{3}$ single crystal and a YSZ thin film on the back side, measured at $400^{\circ} \mathrm{C}$ set temperature.

Before interpreting these measurements, an additional experiment has to be introduced. Fig. 6a displays the impedance spectra measured for Cell Type IIb before and during UV illumination. The analysis of the capacitance indicates that the main arc visible in the spectrum is caused by the $\mathrm{SrTiO}_{3}$ single crystal. Obviously, UV light causes a strong resistance decrease which can be associated with substantial photoconductivity due to UV-induced formation of electrons and holes. Under illumination the conductivity still slightly changes but most striking is the effect found after switching off the voltage (Fig. 6b): The resistance does not jump to its original value before UV light, rather it slowly increases within several ten minutes to its initial value. Since electron-hole recombination is expected on time scales much below one second, this indicates additional defect chemical changes in $\mathrm{SrTiO}_{3}$ during illumination.
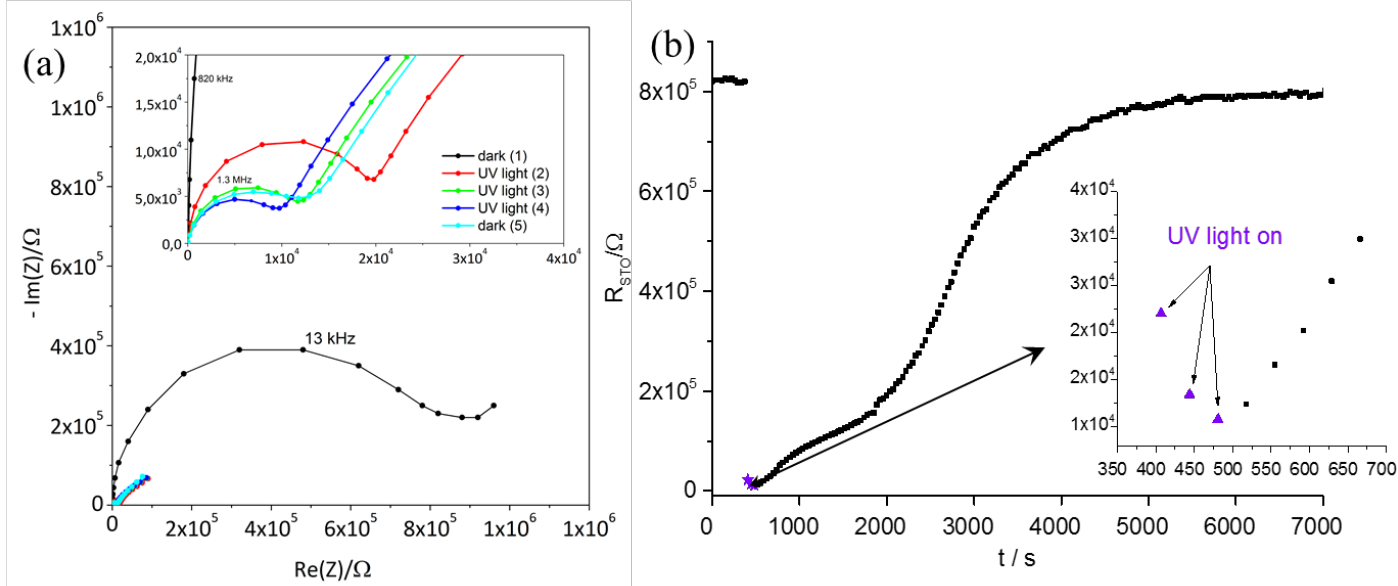

Figure 6. (a) Effect of UV illumination on the $\mathrm{SrTiO}_{3}$ related part of the impedance spectrum of Cell Type IIb at $400^{\circ} \mathrm{C}$ set temperature. The size of the arc shrinks drastically immediately after UV on and further changes under illumination. Relaxation after UV off is very slow. This is also visible in (b) which shows the $\mathrm{SrTiO}_{3}$ resistance analyzed from the corresponding impedance arc. 
In one of the very few studies dealing with defect chemical effects of UV light in oxides at high temperatures, Merkle et.al. showed by conductivity relaxation experiments after $\mathrm{p}\left(\mathrm{O}_{2}\right)$ changes that the oxygen incorporation kinetics of $\mathrm{SrTiO}_{3}$ is strongly accelerated under UV illumination (8). This also suggests that the "equilibrium" oxygen stoichiometry of $\mathrm{SrTiO}_{3}$ in air is different with and without UV light. Assuming that more oxygen is in a gas-equilibrated illuminated crystal, i.e. less oxygen vacancies and more electron holes, we can expect that immediately after switching-off the UV light still more holes are present in $\mathrm{SrTiO}_{3}$. This can explain the strongly enhanced conductivity after UV exposure. Only slowly the surplus oxygen leaves the sample while approaching the equilibrium stoichiometry of a dark $\mathrm{SrTiO}_{3}$ crystal. Hence, our measurements provide a strong hint that semiconducting oxides and thus our MIECs may change their stoichiometry $(\Delta \delta)$ under UV illumination. This is key for understanding the measured voltage responses during and after UV illumination of both Cell Types IIa and IIb, i.e. using $\mathrm{TiO}_{2}$ and $\mathrm{SrTiO}_{3}$.

The supposed processes are sketched in Fig. 7: The very quick first voltage jump (P1) is assumed to be the consequence of a photovoltage developing at the metal/semiconductor interface. Space charges (Schottky contacts) at metal/semiconductor interfaces are known to cause photovoltaic responses $(13,14)$. Additional measurements with Pt electrodes on $\mathrm{SrTiO}_{3}$ reveal a significant change of this part of the response, in accordance with differences of the Schottky barriers of Au and Pt electrodes on $\mathrm{SrTiO}_{3}$. Especially for the thin $\mathrm{TiO}_{2}$ layer on zirconia we also cannot exclude a contribution of the $\mathrm{TiO}_{2} / \mathrm{YSZ}$ interface to the observed photovoltage. However, in contrast to the high temperature solar cell with bottom electrode used in Cell Type I ( $\left.\mathrm{LSCr} / \mathrm{SrTiO}_{3}\right)$, here the voltage is transferred via an ion conductor to the counter electrode. A straightforward characterization of current-voltage curves of the involved photovoltaic effect is thus not possible, any DC current would require electrochemical reactions at interfaces.

The space charge at the MIEC/metal interface should depend on the Fermi level in the MIEC and thus a stoichiometry change of the MIEC under illumination should also affect the space charge and thus the photovoltage. Accordingly, the measured variation of the photovoltage (to less negative values) is at least partly a consequence of the defect chemical changes taking place in an illuminated semiconductor (P2a in Fig. 7). A second consequence of stoichiometry variations under UV is seen after switching-off the UV light: A partly substantial positive voltage remains and this can be interpreted as a Nernstian voltage (P2b in Fig. 7) between the MIEC on YSZ and the gas phase at the counter electrode. Immediately after switching-off UV, the MIEC still exhibits a stoichiometry which differs from that of the equilibrated dark MIEC. This chemical potential difference can be measured as a voltage since an ion conductor is between the MIEC and the counter electrode. Slowly, the MIEC releases its surplus oxygen and the voltage again approaches the value before UV illumination. Accordingly, we see the sum of a photovoltage effect (P1), modified by $\Delta \delta$ (P2a), and a light induced chemical (battery) effect (P2b). We thus have a special kind of battery, consisting of the MIEC electrode, YSZ and the gas at the counter electrode, which can be charged by UV light. 

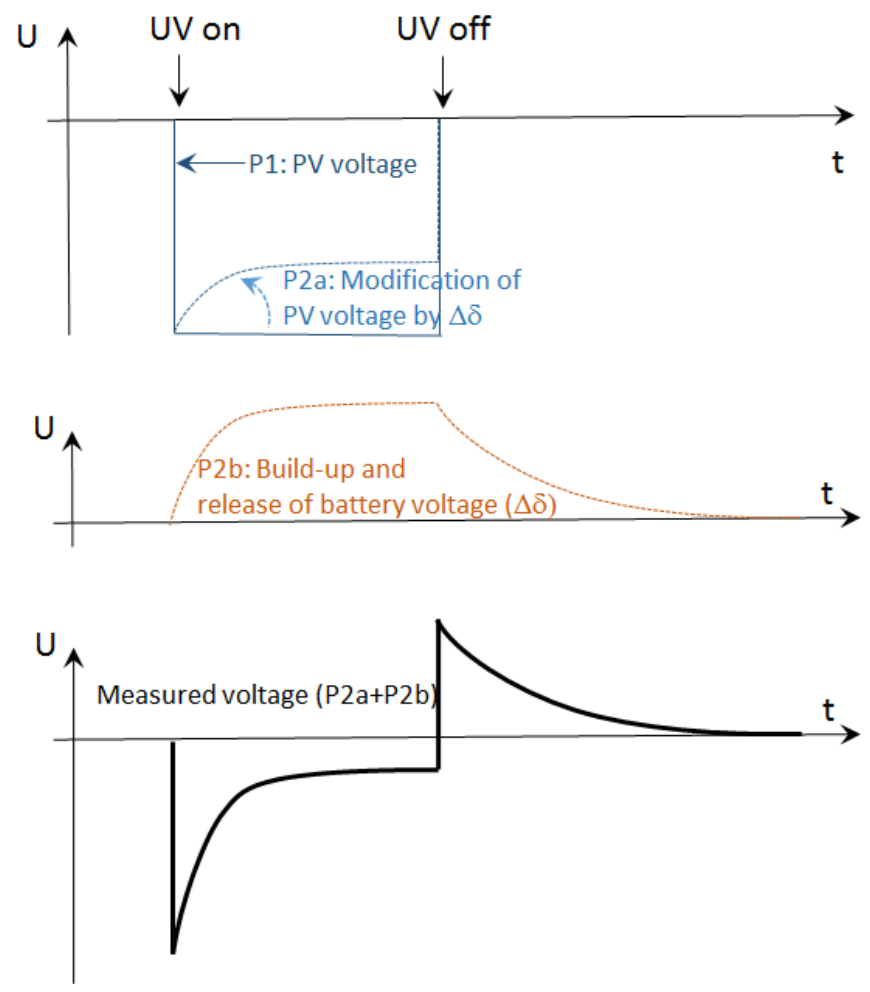

Figure 7. Model explaining the different contributions to the voltage behavior during and after UV illumination. Process 1 (P1) is a purely photovoltaic effect, process 2 (P2) the change of the stoichiometry in the mixed conducting oxide under illumination. P2 affects the photovoltage (P2a) but also leads to the development of a battery-type (Nernstian) voltage (P2b). The bottom sketch shows the resulting total voltage curve.

Unfortunately, both light induced effects (photovoltage and battery voltage) cannot be exploit in terms of significant currents yet, since the kinetics of oxygen exchange and ion transport is slow for the MIECs used here. Thinner and appropriately doped STO layers may improve the situation, even though we failed so far getting substantial photoeffects in thin layers of highly iron doped $\mathrm{SrTiO}_{3}$. Future measurements with other MIECs will show whether reasonable currents and capacities are possible in this kind of light-charged battery. The same is true for testing the cell's potential in terms of an operation as a photo-electrochemical cell with light-driven oxygen pumping.

However, an additional experiment indicates that there may be still another option for obtaining significant photo-induced ionic currents in short-circuited cells. We fabricated one cell with alternating $\mathrm{LSC}$ and $\mathrm{TiO}_{2}$ stripes on zirconia; one pair of stripes is sketched in Fig. 1 (Cell Type IIa*) and also shown in the photograph of Fig. 8. LSC is known to be an excellent oxygen exchange electrode (15). Interestingly, a significant positive voltage is measured between LSC and the bottom electrode when illuminating the entire set-up. Samples having only LSC electrodes did not show such an effect. This indicates that by a mechanism not fully understood yet a voltage resulting at either the gas $/ \mathrm{TiO}_{2}$ interface or the $\mathrm{TiO}_{2} / \mathrm{YSZ}$ interface can be partly transferred to a driving force between the LSC electrode and the counter electrode. This indeed leads to a current when short-circuiting LSC and counter electrode and might enable chemical storage of energy under light. 

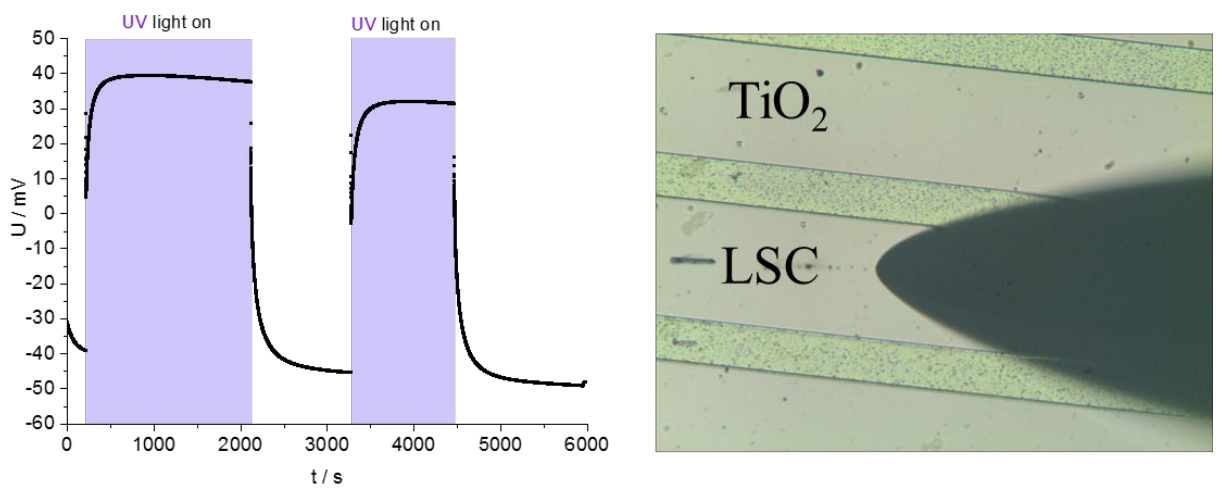

Figure 8. Voltage measured between LSC stripes (see photograph) and the counter electrode of Cell Type IIa* when illuminating the cell, i.e. the $\mathrm{TiO}_{2}$ stripes. Illuminating a cell with LSC only does not lead to a significant voltage effect.

\section{Conclusions}

Several types of effects can cause voltages in UV exposed cells with light absorbing mixed ionic and electronic conducting oxides. A substantial space charge between Srdoped $\mathrm{LaCrO}_{3}$ and $\mathrm{SrTiO}_{3}$ allows fabrication of a high temperature solar cell with open circuit voltages above $900 \mathrm{mV}$ at $400^{\circ} \mathrm{C}$. The corresponding driving force can be directly coupled into a built-in electrochemical cell with one shared electrode and allows oxygen pumping from low to high oxygen partial pressure. Also UV exposed MIECs such as

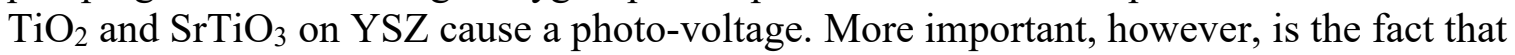
such MIECs change their stoichiometry under illumination. This becomes obvious in conductivity changes and, for MIECs on an ion conductor, in a Nernstian voltage remaining after switching off the UV. These UV-induced defect chemical changes may thus enable a kind of light charged battery as well as oxygen pumping in solid electrolyte based photo-electrochemical cells.

\section{Acknowledgments}

The authors gratefully acknowledge funding by the Austrian Research Promotion Agency (FFG) under project no. 838562 and Austrian Science Funds (FWF), project F4509-N16. Special thanks is also conveyed to Constantia Industries AG and NOVAPECC GmbH for financial support.

\section{References}

1. A. Fujishima, Nature, 238, 37 (1972).

2. J. Mavroides, J. Kafalas, and D. Kolesar, Appl. Phys. Lett., 28, 241 (1976).

3. J. Nowotny, C. Sorrell, T. Bak, and L. Sheppard, Solar Energy, 78, 593 (2005).

4. G. Wang, H. Wang, Y. Ling, Y. Tang, X. Yang, R. C. Fitzmorris, C. Wang, J. Z. Zhang, and Y. Li, Nano Letters, 11, 3026 (2011). 
5. A. Valdes, J. Brillet, M. Grätzel, H. Gudmundsdottir, H. A. Hansen, H. Jonsson, P. Klüpfel, G.-J. Kroes, F. Le Formal, and I. C. Man, Phys. Chem. Chem. Phys., 14, 49 (2012).

6. F. E. Osterloh, Chem. Mater, 20, 35 (2008).

7. J. Gan, X. Lu, and Y. Tong, Nanoscale, 6, 7142 (2014).

8. R. Merkle, and J. Maier, Angew. Chemie Int. Ed., 40, 2126 (2001).

9. H. W. Gundlach and K.E. Heusler, Zeitschrift f. Phys. Chem., 119, 213 (1980).

10. X. Ye, J. Melas-Kyriazi, Z. A. Feng, N. A. Melosh, W. C. Chueh, Phys. Chem. Chem. Phys., 15, 15459 (2013).

11. G. C. Brunauer, B. Rotter, G. Walch, A. K. Opitz, G. Ponweiser, J. Summhammer, and J. Fleig, Adv. Funct. Mat., 26, 120 (2016).

12. T. M. Huber, A.K. Opitz, M. Kubicek, H. Hutter, and J. Fleig, Solid State Ionics, 268, 82 (2014).

13. D. L. Pulfrey and R. F. McOuat, Appl. Phys. Lett., 24, 164 (1974).

14. S. S. Li, Jpn. J. Appl. Phys., 17, 291 (1978).

15. G. M. Rupp, A. Limbeck, M. Kubicek, A. Penn, M. Stöger-Pollach, G. Friedbacher, and J. Fleig, J. Mater. Chem., A 2, 7099 (2014). 